\title{
Hukkakauran siemenien itävyyden säilymisriski maassa
}

\author{
Heikki Jalli ${ }^{1)}$ ja Eeva Saarisalo' \\ ${ }^{1)}$ MTT, Kasvintuotannon tutkimus, R-talo, 31600 Jokioinen, heikki.jalli@mtt.fi \\ ${ }^{2)}$ Maa-ja metsätalousministeriö, Elintarvike- ja terveysosasto, PL 30, 00023 Valtioneuvosto, \\ eeva.saarisalo@mmm.fi
}

\section{Tiivistelmä}

Hukkakaura on yksivuotinen rikkaheinä, joka keväällä orastuttuaan kasvaa aluksi viljaa hitaammin. Hukkakauran siemen itää ja orastuu hitaasti, mutta varmasti, kun olosuhteet ovat sopivat ja itämiskypsyys on saavutettu. Hukkakaura kehittää ensin voimakkaan juuriston, jonka turvin se myöhemmin kasvaa nopeasti viljan seassakin muuta kasvustoa korkeammaksi.

Lokakuussa 2005 ja 2006 Jokioisilla kylvettiin 200 hukkauransiementä hienolla hiedalla täytettyihin verkkopohjallisiin kehikkoiin. Kehikot upotettiin reunojaan myöten peltomaahan. Kylvösyvyydet olivat $2,5 \mathrm{~cm}$ ja pinta. Hukkakauran siementen taimettumista seurattiin kunnes siemeniä ei enää taimettunut.

Hukkakauran taimettuminen ja taimettumisrytmi vaihtelee vuosittain.

Maahan mullatun hukkakauran siemenen taimettuminen on varmempaa kuin maan pinnalla olevan siemenen. Syksyn kosteissa ja lämpimissä oloissa voivat maahan mullatut hukkakauransiemenet taimettua huomattavan runsaasti.

Maan pinnalla olevien siementen taimettuminen voi myöhästyä kasvukaudella. Pienet taimet voivat jäädä huomaamatta kemiallisen torjunnan aikaan ja myös mullattuja siemeniä useammat pinnalla olevat voivat taimettua vasta herbisidikäsittelyn jälkeen.

Asiasanat: hukkakaura, siemen, itäminen, taimettuminen 


\section{Johdanto}

Hukkakaura on yksivuotinen rikkaheinä, joka keväällä orastuttuaan (Thurston 1953) kasvaa aluksi viljaa hitaammin. Hukkakauran siemen itää ja orastuu hitaasti, mutta varmasti, kun olosuhteet ovat sopivat ja itämiskypsyys on saavutettu (Hilli 1959). Hukkakaura kehittää ensin voimakkaan juuriston, jonka turvin se myöhemmin kasvaa nopeasti viljan seassakin muuta kasvustoa korkeammaksi (Salonen 1998).

Hukkakaura ei ole vaatelias maalajin suhteen, mutta maan happamuudelle hukkakaura on jossain määrin arka, vaikka Holm ym. (1977) mukaan se sietää happamuutta pH 4,5. Kasvaessaan happamissa oloissa hukkakaura saa ohraan nähden kilpailuedun ja hukkakaurayksilöt kasvavat isommiksi kuin neutraaleissa oloissa (Thurston 1962b).

Hukkakaura viihtyy multamailla, missä huomattava osa maan pintakerroksen siemenistä orastuu. Siemenessä on riittävästi vararavintoa itämiseen jopa 15-20 cm:n syvyydestä (Thurston 1956, 1966). Tällaiset yksilöt orastuvat tavallisesti muita hukkakauroja myöhemmin ja voivat näin välttää kemiallisen torjunnan (Salonen 1998). Hukkakaura kuuluu rikkakasviryhmään, jonka siemenpankki pienenee nopeasti. Noin $80 \%$ siemenistä epäonnistuu taimettumisessa tai kuolee vuosittain, mutta suuri osa myös taimettuu, noin 15 \% vuosittaisesta siemenpankista (Barralis ym 1988).

On todennäköistä, että jo ennen tuleentumista varisevat, esimerkiksi maitotuleentumisasteella olevat siemenet ovat itämiskykyisiä. Hukkakauran torjunnan tekee ongelmalliseksi se, että maahan varisseiden siementen määrää ei tiedetä eikä myöskään sitä, kuinka monen vuoden ajan ne säilyvät maassa elinkykyisinä (Auranen 1993). Yksilöissä, joissa on useampia röyhyjä, voi siemenmäärä edullisissa oloissa nousta jopa tuhanteen (Hilli 1959).

Maassa olevien siementen itämislepo on eriasteista, muutamat siemenet saattavat itää syksyllä maan pinnalla, toiset mahdollisesti seuraavana keväänä tai myöhempinä vuosina, kun siemenet maan muokkauksen jälkeen sattuvat sopivaan kohtaan lähelle maan pintakerrosta (Auranen 1993). Siemenen itämislepoon vaikuttavat monet tekijät, esim. maan lämpötila ja kosteus sekä, miten syvällä siemen on maassa. Syvälle hautaaminen ja rauhaan jättäminen aiheuttavat siemenen lepotilan (Thurstonin 1956). Hukkakauran siemenistä on yleensä yli 90 \% itämislevossa (Thurston 1953).

Hukkakaura, kuten muidenkin rikkakasvien siementen peittyminen maalla lisää taimettumista (Chadoeuf ym 1980) ja toisaalta siementen elinikä pitenee (Conn ja Farris 1987, Miller ja Nalevwaja 1990). Pessalan (1978a) mukaan käytännössä vuosittain taimettuvien siementen osuus on enemmän riippuvainen siemenen hautaamissyvyydestä kuin esimerkiksi sääoloista. Typpilannoitus lisää maahan hautautuneiden siementen tuhoutumista (Miller ja Nalevwaja 1990). Vuosittaiset suuret erot taimettumismäärissä johtunevat siementen paikan muuttumisesta maata muokattaessa, kuten havaitsivat Gummesson ja Svensson (1973) muokatessaan pintamaata hyvin syvälle

Wilsonin (1978) mukaan maan hukkakauran siementen varasto koostuu pääosin kahtena, kolmena viime kasvukautena maahan joutuneista siemenistä.

Siemenen elinikä maassa on yleensä alle kuusi vuotta (Wilson 1981, Salonen 1998). Ensimmäiset kaksi vuotta siemenet säilyivät paremmin savimaassa kuin hiedassa tai multamaassa, jonka jälkeen kolmantena vuonna tapahtui nopea siementen tuhoutuminen. Tämän jälkeen maassa oli elinkykyisiä siemeniä 5-6 \% alkuperäisestä määrästä (Pessala 1978b).

Saastunnan pieneneminen alkaa nopeana ensimmäisinä vuosina, mutta ajan kuluessa taimettuvien osuus koko siemenvarastosta pienenee (Thurston 1958). Myös Banting (1966) havaitsi siementen elinkyvyn nopean heikkenemisen kahtena ensimmäisen vuotena hautaamisesta, jonka jälkeen siementen kuoleminen hidastui. Muutamat siemenet olivat hengissä vielä seitsemän vuoden kuluttua.

Ensimmäisenä keväänä 20 \% itämissyvyydessä olevista siemenistä kuolee. Lämpötilan vaihtelu pitkällä ajanjaksolla murtaa siemenen lepotilan. Jos itämislepo on loppunut, siemen jatkaa taimettumista, vaikka olisikin hautautunut liian syvälle (Koprac 1966). Wilsonin (1981) mukaan toinen siementen tuhoutumishetki on silloin, kun siemenet itämisen jälkeen eivät pysty taimettumaan.

Hukkakaura tuleentuu aikaisin ja varistaa herkästi siemenensä maahan. Näistä siemenistä enintään 5-10 \% itää samana syksynä, mutta useimmat säilyvät itämislevossa talven yli (Salonen 1998).

Hukkakauran siementen taimettuminen lisääntyy kevään edetessä (Chadoeuf ym 1980). Syksyllä orastuvat hukkakaurat eivät talvehdi. Jos peltoa ei muokata syksyllä, tuhoutuu myös osa maan pinnalle jääneistä siemenistä talven aikana, joten suorakylvö auttaa hukkakauran torjunnassa (Phipps \& Roebuck 1980, Salonen 1998). 
Vuonna 1974 aloitettu koe osoitti (Pessala 1978b), että eri maalajien välillä ei ollut suuria eroja hukkakauran itävyydellä. Savimaassa elävien siementen lukumäärä väheni hitaammin kuin hieta- ja multamaassa, mikä osaksi selittyy siementen heikommasta orastuvuudesta savimaassa. Hukkakauran siemenet säilyvät jonkin verran kauemmin syvemmällä maassa kuin lähempänä pintaa.

Eniten hukkakauran siemeniä taimettui kolmen koevuoden aikana savi ja hietamaalta $2,5 \mathrm{~cm}$ syvyydestä ja multamaalta 7,5 cm syvyydestä. Syvyyteen 2,5-12,5 cm kylvetystä siemenistä iti kaiken kaikkiaan kolmen vuoden jaksolla savimaalla $11 \%$, hietamaalla $34 \%$ ja multamaalla $55 \%$. Maan pinnalla olleista siemenistä savimaalla taimettui $23 \%$, hietamaalla $24 \%$ ja multamaalla $18 \%$ siemenistä (Pessala 1978a).

Hukkakaura taimettuu maan pintakerroksista ja jos maata muokataan vain matalaan, valtaosa siemenistä itää maahan joutumistaan seuraavana keväänä, kun varisseiden siemenien itämislepo häviää (Wilson 1981).

\section{Aineisto ja menetelmät}

Lokakuussa 2005 ja 2006 Jokioisilla kylvettiin 200 hukkauransiementä hienolla hiedalla täytettyihin verkkopohjallisiin kehikkoiin. Kehikot upotettiin reunojaan myöten peltomaahan. Kylvösyvyydet olivat $2,5 \mathrm{~cm}$ ja pinta, toistoja oli neljä (Kuva 1).

Taimettumista seurattiin kylvösyksystä lähtien ja taimettuneet hukkakaurat poistettiin kehikoista laskennan jälkeen. Havaintoja tehtiin syksyllä ennen lumentuloa, kesäkuun alkupuolella ja kesäheinäkuun vaihteessa. Havainnointia jatkettiin kunnes hukkakauraa ei enää taimettunut. Taimettuneet hukkakaurat poistettiin, eivätkä ne tuottaneet uusia siemeniä.

Kumpanakin kylvövuonna käytettiin samaa siemenerää, jonka itävyys oli 74 \%.

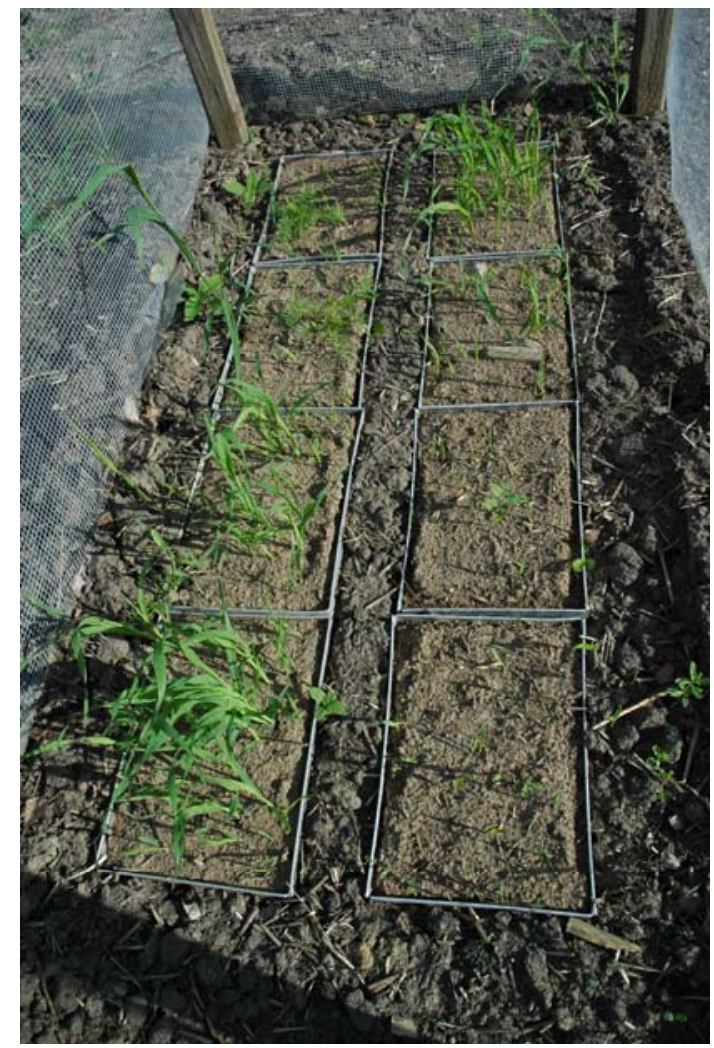

Kuva 1. 200 hukkakauran siementä kylvettiin verkkopohjaisiin kehikoihin 


\section{Tulokset ja tulosten tarkastelu}

Syksyllä 2005 kylvetyt hukkauran siemenet eivät itäneet kylvösyksynä. Seuraavana kesänä hukkakauran torjunta-aikaan mennessä taimettuneita oli $2,5 \mathrm{~cm}$ syvyyteen kylvetyistä siemenistä keskimäärin 20 \% ja pinnalla olleista lähes $10 \%$. Syyskesään mennessä kummastakin kylvöstä taimettui lisäksi 13 - 14 siementä eli noin $7 \%$ (Kuva 3.).

Syksyllä 2005 kylvettyjen siementen taimettuminen jatkui ja $2,5 \mathrm{~cm}$ syvyydestä taimettui $2 \%$ ja kesällä 2007 vielä $2 \%$. Kesän 2007 oloissa maan pinnalla olleiden hukkakauransiemenien taimettuminen painottui myöhäiskesään, mutta $2,5 \mathrm{~cm}$ syvyyteen kylvetyt siemenet taimettuivat pääosin aikaisin kesällä. Kokonaistaimettuminen oli maan pinnalla $15,5 \%$ ja $2,5 \mathrm{~cm}$ syvyydestä $26,5 \%$.

Syksyn 2006 oloissa $2,5 \mathrm{~cm}$ syvyyteen kylvetyistä hukkakauran siemenistä taimettui joulukuun alkuun mennessä 62 kappaletta eli 31 \% (Kuva 4). Seuraavan kesäkuun alkupuolelle mennessä maahan kylvetyistä siemenistä taimettui $17,5 \%$ ja maan pinnalle levitetyistä $27,3 \%$. Syyskesään mennessä 2,5 cm syvyyteen kylvettyjen siementen taimettuminen lisääntyi vain 3,3\%, mutta maan pinnalla olleiden $16,2 \%$.

2006 kylvettyjen siementen taimettuminen loppui syksyyn 2007. Kokonaistaimettuminen oli maan pinnalla $43 \%$ ja $2,5 \mathrm{~cm}$ syvyydestä $52 \%$.

Kokeessa hukkakauran taimettuminen hietamaalla oli, etenkin syksyllä 2006 kylvettynä, runsasta verrattuna Pessalan (1978a) saamiin tuloksiin

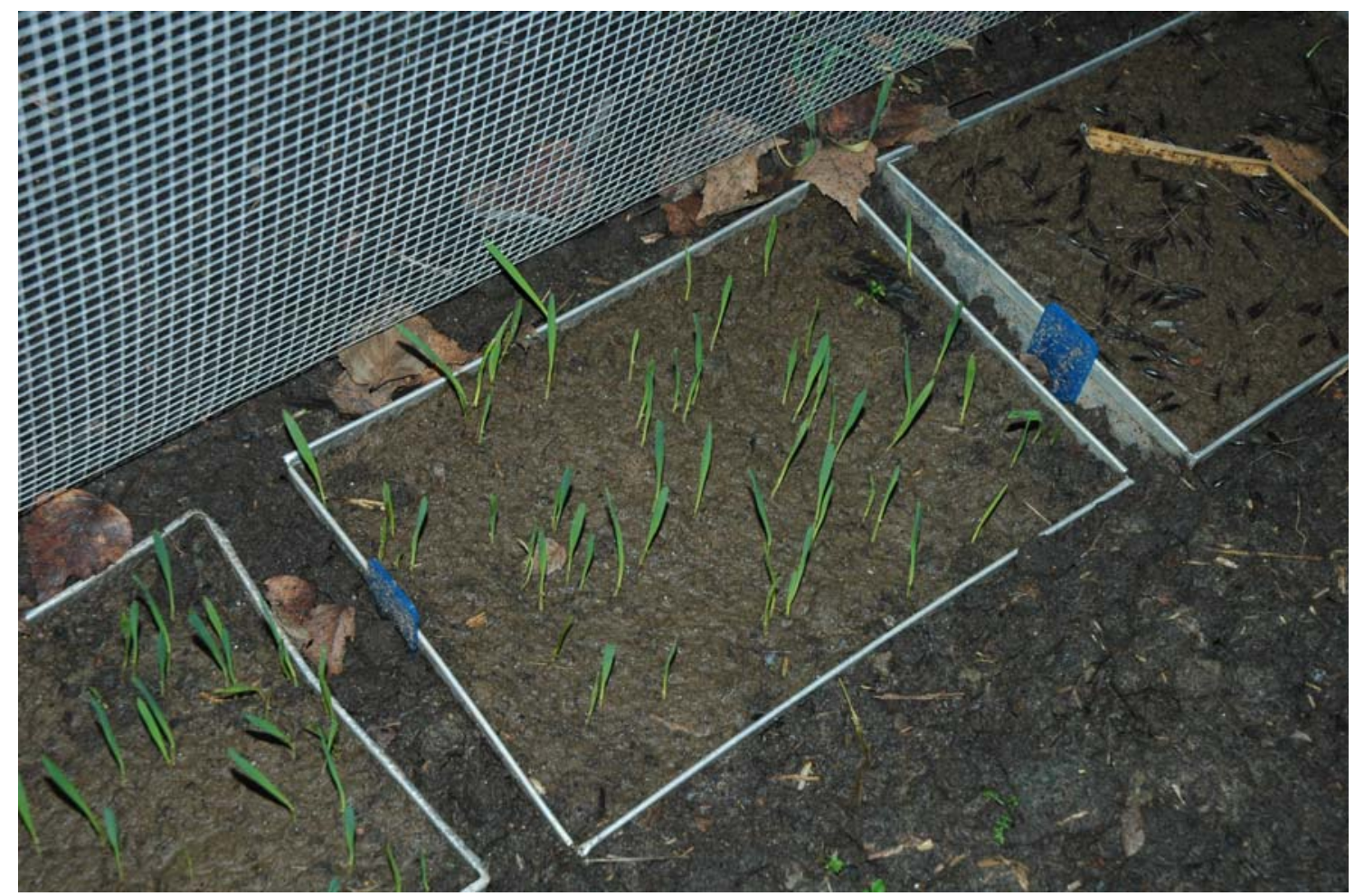

Kuva 2. Syksyn 2006 lämpimissä ja kosteissa oloissa 2,5 cm syvyyteen kylvetyistä hukkakauran siemenistä taimettui joulukuun alkuun mennessä 62 kappaletta/ 200 siementä eli $31 \%$ 


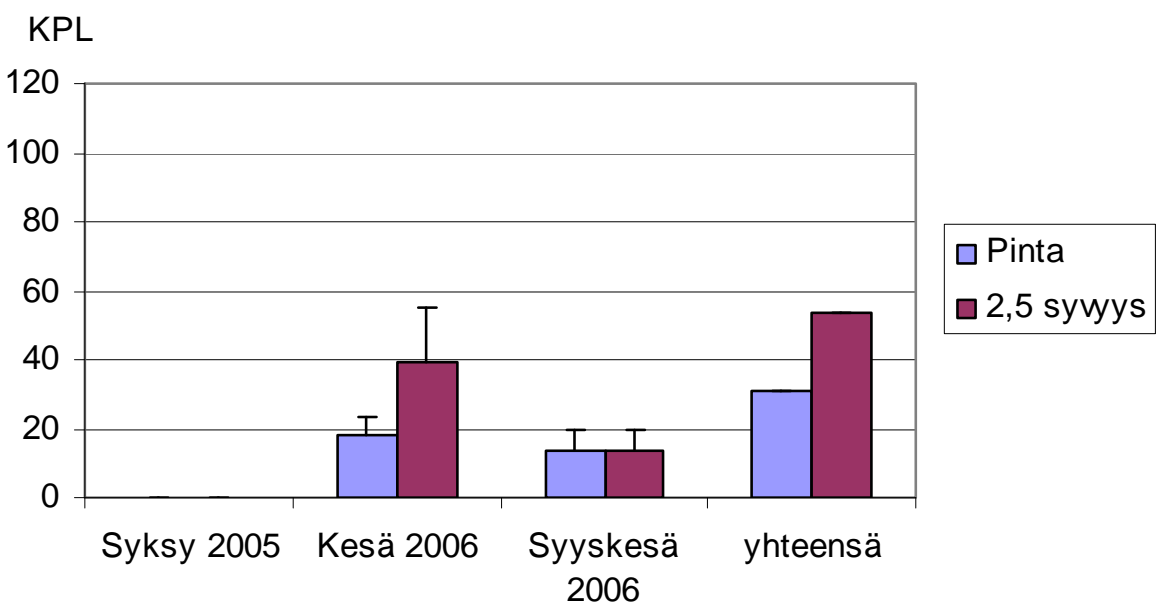

Kuva 3. Taimettuminen/200 siementä. Syksyllä 2005 kylvettyjen hukkakauran siementen taimettuminen seuraavana kesänä. Kuvan ulkopuolella taimettuminen jatkui kesällä 2007. Pylväiden päälle on merkitty keskiarvon keskihajonta.

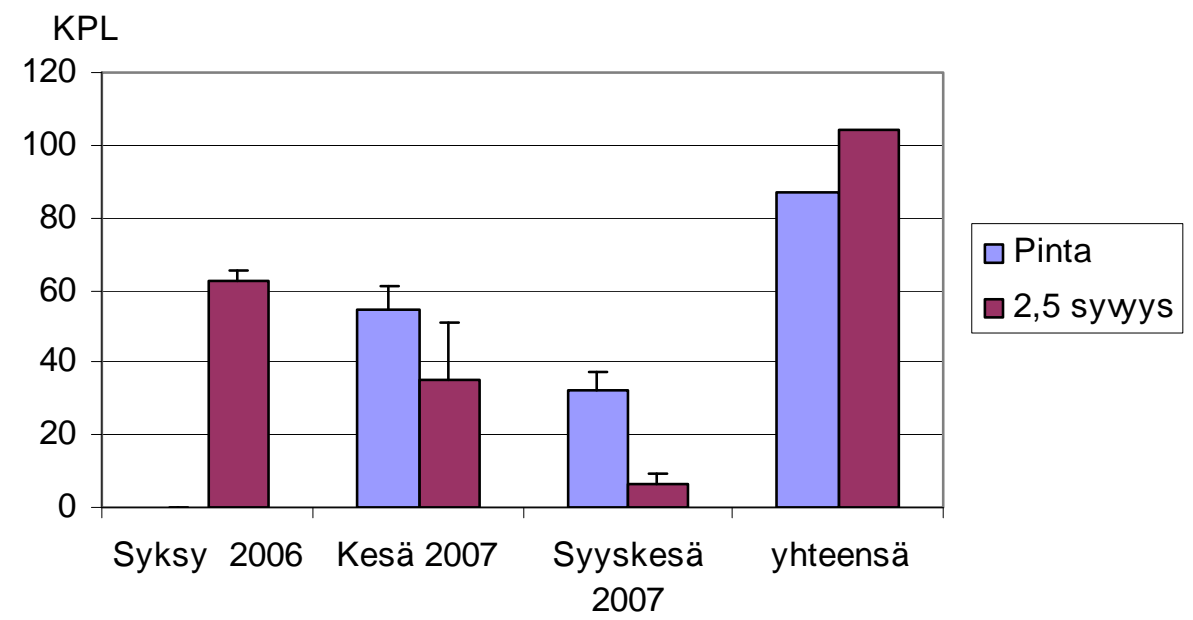

Kuva 4. Taimettuminen/200 siementä. Syksyn 2006 oloissa 2,5 cm syvyyteen kylvetyistä hukkakauran siemenistä taimettui joulukuun alkuun mennessä 62 kappaletta eli $31 \%$. Pylväiden päälle on merkitty keskiarvon keskihajonta.

\section{Johtopäätökset}

Hukkakauran taimettuminen ja taimettumisrytmi vaihtelee vuosittain. Kosteissa ja lämpimissä oloissa voivat maahan mullatut hukkakauransiemenet taimettua huomattavan runsaasti.

Maahan mullatun hukkakauran siemenen taimettuminen on varmempaa kuin maan pinnalla olevan siemenen.

Maan pinnalla olevien siementen taimettuminen voi myöhästyä kasvukaudella. Pienet taimet voivat jäädä huomaamatta kemiallisen torjunnan aikaan ja myös mullattuja siemeniä useammat voivat taimettua vasta herbisidikäsittelyn jälkeen

Maan pinnalla olevien siementen taimettuminen voi myöhästyä kasvukaudella. Pienet taimet voivat jäädä huomaamatta kemiallisen torjunnan aikaan ja myös mullattuja siemeniä useammat pinnalla olevat voivat taimettua vasta herbisidikäsittelyn jälkeen

\section{Kirjallisuus}

Auranen, M. 1993. Hukkakaura sopeutumisen ja lisääntymisen mestari. Maaseudun Tulevaisuus 58: 2. ISSN 0355-3787 
Banting, J.D. 1966. Studies on the persistence of Avena fatua. Canadian journal of plant science. 46: 129-140. ISSN 0008-4220

Chadoeuf, R., Magriere, J.P., Lonchamp, J.P. \& Barralis, G. 1980. Comparative evolution of the germination capacity of weed seeds when buried or dry-stored. Comparative evolution of the germination capacity of weed seeds when buried or dry-stored. Proceedings-of-the-6th-International-Colloquium-on-Weed-Ecology,Biology-and-Systematics,-organized-by-COLUMA-EWRS. p. (oume): 103-112.

Conn, J.S. \& Farris, M.L. 1987. Seed viability and dormancy of 17 weed species after 21 months in Alaska. Weed Science 35: 524-529.

Gummesson, G \& Svensson, K. 1973. Tvåskiktsplog och plog med förplog vid bekämpning av flyghavre och kvickrot. Lantbrugshögskolans meddelanden. Serie A 202. Teknik 13. p. 1-32.

Hilli, A. 1959. Hukkakauran (Avena fatua L.) esiintymisestä Suomessa. Suomen maataloustieteellisen seuran julkaisuja, Acta Agralia Fennica. 94: 299-315.

Holm, LR.G., Plucknett, D.L., Pancho, J.V \& Herberger, J.P. 1977. The world's worst weeds. Honolulu: The University press of Hawaii. 609 p. ISBN 0-8248-0295-0.

Kropac, Z. 1966. Estimation of weed seeds in arablesoils. Pedobiologia. 6: 105-128. ISSN 0031-4056

Miller, S.D. \& Nalewaja, J.D. 1990. Influence of burial depth on wild oats (Avena fatua) seed longevity. Weed Technology 4: 514-517.

Pessala, B. 1978a. Longvity of Avena fatua seeds in the field. In Weeds and weed control. 1 Reports. 19th Swedish weed conference, Upsala 1-3 Fbruary 1978. UpsalaSveriges lantbrukuniversitetet. C15-24. ISBN 917088-856-6

Phipps, P. \& Roebuck, J.F. 1980. Agricultural development and advisory service/weed research organization Avena fatua case studies. In: Proseedings 1989 Britesh Crop Protection Conference-Weeds. p. 407-414.

Salonen, J. 1998. Hukkakaura. In: Irmeli Markkula (toim.). Ajankohtaisia kasvinsuojeluohjeita. Kasvinsuojeluseuran julkaisuja 91: p. 18-22.

Thurston, J.M 1953. Biology of wild oats. Report of the Rothamsted experimental station for 1952. 68-71.

- 1956. Wild oats. Report of the Rothamsted experimental station for 1955. 73-74.

- 1958. Wild oats. Report of the Rothamsted experimental station for 1957. 95-93.

- 1962b. The effect of competition from cereal crops on the germination and growth of Avena fatua L. in naturally infested field Weed Reserch 2:129-207.

- 1966. Survival of seeds of wild oats (Avena fatua L. and Avena ludoviciana Dur.) and charlock (Sinapis Arvensis L.) in soil under leys. Weed research 6: 67-80. ISSN 0043-1737.

Wilson, B.J. 1981. The influence of reduced cultivations and direct drilling on the long-term decline of a population of Avena fatua L. in spring barley. Weed Research 21: 23-28. ISSN 0043-1 